\title{
Bovine cysticercosis and human taeniosis in South-west Shoa zone of Oromia Region, Ethiopia
}

${ }^{1}$ Adugna Tadesse, ${ }^{*}{ }^{2}$ Yacob Hailu Tolossa, ${ }^{2}$ Dinka Ayana and ${ }^{2}$ Getachew Terefe

${ }^{1}$ Oromia Livestock Agency, P.O.Box, 7979

${ }^{2}$ Addis Ababa University, College of Veterinary Medicine and Agriculture, Department of Pathology and Parasitology, P.O. box 34, Debre-zeit, Ethiopia

* Corresponding author: Yacob Hailu, e-mail: yamilaya2008@gmail.com

\section{Abstract}

A cross-sectional study was conducted in cattle slaughtered at Sebeta, Tulu Bolo and Weliso abattoirs in southwest shoa zone of Oromia region, Ethiopia to estimate the prevalence of bovine cystiercosis using routine meat inspection method, and questionnaire surveys were undertaken to assess the status of taeniosis and associated risk factors in human in these towns. Accordingly, out of 1216 carcasses examined, $4.6 \%$ were found infected with Cysticercus bovis. Among the positive cases for $C$. bovis, $39.3 \%$ were viable and $60.7 \%$ were non-viable cysts while it was more prevalent in the heart and tongue (39.3\% and $30.4 \%$, respectively) than in the diaphragm and liver. Out of 392 respondents, $55.1 \%$ had contracted $T$. saginata at least once in the past years. The prevalence was significantly higher in adults $(>20$ years) than youngsters $(<20$ years $)(\mathrm{P}<0.001)$, in male than females $(\mathrm{P}=0.046)$, in Christian than Muslim community $(\mathrm{P}=0.011)$, in butchers and abattoir workers than in other occupation $(\mathrm{P}<0.001)$, in illiterate than in literate and university graduates $(\mathrm{P}=0.001)$ and in raw meat consumers than in others $(\mathrm{P}<0.01$. In conclusion, bovine cysticercosis caused by $C$. bovis and associated human taeniosis are important problems in the study areas. Improvement in meat inspection procedures and sanitary conditions in the study areas are needed.

Key words: Cysticercosis, Cattle, Human, Taeniosis, Ethiopia. http://dx.doi.org/10.4314/evj.v17i2.9 


\section{Introduction}

It is well documented that a number of food born parasitic infections prevail worldwide. Among these are Sarcosistis spp., Taenia spp. and Trichinella spp, which human beings acquire by eating raw or undercooked meat infected with cyst stages of these parasites. In developing countries a large proportion of carcasses escape meat inspection because it is not practiced or because the animals are not slaughtered in abattoirs (Dorny et al., 2009).

Human taeniosis/Taenia saginata is a cosmopolitan parasitic disease found in industrialized countries as well as in developing countries. Taeniosis is more common in populations/age groups that consume raw or undercooked beef (Murrell, 2005). In Eastern African countries like Ethiopia up to $70 \%$ of the population reports to have been infected with a tapeworm (Nigatu Kebede et al., 2009) while in developed western countries much lower prevalence $(0.01 \%$ to $10 \%)$ were recorded (Cabaret et al., 2002; Dorny et al., 2007). Similarly, bovine cysticercosis, the source of infection for human beings, is highly prevalent in developing countries including sub-Saharan Africa and Ethiopia. The prevalence of bovine cysticercosis in Ethiopia showed quite variable results with localities ranging from relatively lower prevalence of $3.1 \%$ in central Ethiopia (Markos Tibo, 2001) to as high as 26.25 at Awassa (Fufa Abunna et al., 2008) whereas in Europe it ranges from $0.007 \%$ to $6.8 \%$ (Dorny et al., 2000; Cabaret et al., 2002). Differences in geographical isolates of the parasite and in the breed and age of cattle have been suggested as possible factors affecting the distribution of Cysticercus bovis (Pawlowski and Murrell, 2001).

Economic losses due to bovine cysticercosis are associated with total condemnation of carcasses with generalized infestation and downgrading of carcasses which are subjected to refrigeration, in addition to the cost of refrigeration and extra handling and transport (Giesecke, 1997; Dorny et al., 2009). The treatment cost for human taeniosis and costs of manufacturing of drugs have significant contribution in estimation of economic losses (Cabaret et al., 2002). 
Although a number of data have been generated on T. saginata/taeniosis and bovine cysticercosis in different parts of Ethiopia (Markos Tibo, 2001; Hailu Degefu, 2005; Fufa Abunna et al., 2008; Nigatu Kebede et al., 2009), these works have not covered the South Western Zones of Oromia region. Cultural and religious practices with respect to beef consumption are expected to vary in different parts of the country and this was the basis for initiating a study on the epidemiology and public health impacts of taeniosis and cysticercosis in the South Western Zones of Oromia Region of Ethiopia. The study aimed at estimating the prevalence of bovine cysticercosis and human taeniosis, determining organ distribution of C. bovis and identifying major risk factors associated with human taeniosis in Sebeta, Tulu Bolo and Weliso towns of southwest shoa zone of Oromia region, Ethiopia.

\section{Materials and Methods}

\section{Study area}

The study on Taenia saginata taeniosis/bovine cysticercosis was conducted in three districts of south west Shoa zone (Oromia region) namely, Sebeta, Tulu Bolo and Weliso. These towns are located at latitude/longitude of $8.917^{\circ} \mathrm{N} 38.617^{\circ} \mathrm{E}, 8^{\circ} 40^{\prime} \mathrm{N} 38^{\circ} 13^{\prime} \mathrm{E}$ and $8^{\circ} 31^{\prime} \mathrm{N} 38^{\circ} 6^{\prime} 0 \mathrm{E}$, and at about 23 $\mathrm{kms}, 80 \mathrm{~km}$ and $114 \mathrm{~km}$ from the capital Addis Ababa, respectively.

Study population

The study animals for the abattoir survey were indigenous beef cattle brought mainly from central highlands of south west Shoa and west Shoa zones. They are handled under extensive management system on communal pasture land. These are the main sources of meat supply to Sebeta, Tulu Bolo and Weliso towns. Because of owners' discomfort on multiple incisions for the thorough examination of major muscles, only the masseter muscle and internal organs such as tongue, heart, liver and diaphragm were used as indicators of the presence of cysts in the carcass. For the questionnaire surveys, the target populations were residents of Sebeta, Tulu Bolo and Weliso towns. 
Study design and sampling

A cross-sectional study was conducted using routine meat inspection technique in municipality slaughter houses for the presence of $C$. bovis in cattle slaughtered at Sebeta, Tulu Bolo and Weliso. Meat inspection was made in accordance with the procedures of Ethiopian Ministry of Agriculture Meat inspection Regulation (1972) for the detection of $T$. saginata/Cysticercus bovis. Moreover, a cross-sectional study was conducted by a structured questionnaire survey to assess the prevalence of T. saginata/taeniosis, associated potential risk factors and its public health importance. The sample size for all abattoirs and questionnaire surveys were determined using the formula described by (Thrusfield, 2005) at 95\% confidence interval and 5\% absolute precision. Since there was no previous data on the prevalence of cysticercosis/taeniosis in the study areas, expected prevalence was taken as 50\%. Accordingly, for each study Woreda, 384 samples were expected. However, actual sapling was done on 390 to 420 carcasses making a total sample size of 1216 beef cattle examined using routine meat inspection method for the presence of Cystiercus bovis. Similarly, by using the formula given by Arsham (2002) $\left(0.25 / \mathrm{SE}^{2}\right.$, $\mathrm{SE}=5 \%$ ), the sample size for the questionnaire survey was expected to be 100 for each site. However, to accommodate the different classifications of risk factors the total number was increased to 392 individuals who were selected based on convenience and interviewed on topics related to taeniosis and major risk factors. Efforts were made to include respondents of different age, sex, religion and occupation. Age of respondents was categorized as (young: $<20$ years of age, and adults: $>20$ years of age). Similarly, religion was broadly classified as Christian and Muslim where as occupation was subdivided into farmers, merchants, butchers and abattoir workers, civil servants and students. Data were also classified according to education levels of the respondents as illiterate (without formal education), literate (elementary up to high school) and graduates (colleges and universities).

Data analysis

Abattoir data were collected and recorded on Microsoft Excel spread sheet. The outcome variables for the abattoir study were cases of cysticercosis 
the study were analyzed using SPSS (2002) statistical software. Descriptive statistics for associations was analyzed using Chi square test $\left(\chi^{2}\right)$. The prevalence of the disease was determined while various potential risk factors and the most significant independent variables for cysticercosis in animals and $T$. saginata in humans were analyzed by general linear model logistic regression analysis using STATA version 7 (Stata Corp, 2001).

\section{Results}

\section{Abattoirs survey}

Out of the 1216 inspected cattle carcasses in the three municipal abattoirs, 112 animals had varying number of $C$. bovis with an overall prevalence of $4.6 \%$ (Table 1). Within positive animals, the prevalence of $C$. bovis in the heart and tongue was much higher than in masseter, diaphragm and liver.

Table 1: Prevalence of C. bovis in Sebeta, Weliso and Tulu Bolo municipality abattoirs

\begin{tabular}{lccc}
\hline Abattoir & No. of inspected carcass & No of positive & Prevalence (\%) \\
& & & \\
\hline Sebeta & 400 & 17 & $4.25 \%$ \\
Weliso & 430 & 23 & $5.3 \%$ \\
\hline
\end{tabular}

Moreover, of the 56 C. bovis cysts isolated during the study, 22 (39.3\%) were viable and $34(60.7 \%)$ were non viable (Table 2$)$. 
Table 2: Proportion of infected, viable and non-viable cysts of $C$. bovis in different organs from the 56 positive animals in Sebeta, Weliso and Tulu Bolo municipality abattoirs.

\begin{tabular}{lccccc}
\hline Organ infection & $\begin{array}{l}\text { Tongue } \\
\text { No (\%) }\end{array}$ & $\begin{array}{l}\text { Heart } \\
\text { No (\%) }\end{array}$ & $\begin{array}{l}\text { Liver } \\
\text { No (\%) }\end{array}$ & $\begin{array}{l}\text { Masseter } \\
\text { No (\%) }\end{array}$ & $\begin{array}{l}\text { Diaphragm } \\
\text { No (\%) }\end{array}$ \\
\hline Overall & $17(30.4)$ & $23(41.0)$ & $2(3.6)$ & $8(14.3)$ & $6(10.7)$ \\
Viable cyst (\%) & $7(41.2)$ & $9(39.1)$ & $1(50.0)$ & $3(37.5)$ & $2(10.7)$ \\
Non-viable cyst (\%) & $10(58.8)$ & $14(60.9)$ & $1(50.0)$ & $5(62.5)$ & $4(66.7)$ \\
\hline
\end{tabular}

Questionnaire survey

Among the 392 voluntary respondents interviewed from the three selected study areas, $55.1 \%$ had experienced $T$. saginata infection, of which $90 \%$ and $10 \%$ reported using modern drugs and traditional medication for treatment respectively.

The interaction of respondent sex and prevalence of taeniosis was evaluated during the interview. Accordingly, it was found that reported cases were more prevalent in male respondents $(58.4 \%)$ than in females $(25.9 \%)$ $\left(\mathrm{P}<0.05, \chi^{2}=3.988\right)$.

There was significant association between prevalence of taeniosis and religion ( $\mathrm{P}=0.011$ and $\left.\chi^{2}=6.452\right)$; being higher in Christian respondents than in Muslim respondents (Table 3).

Table 3: Prevalence of $T$. saginata among Muslim and Christian respondents.

\begin{tabular}{lccc}
\hline & \multicolumn{3}{c}{ Taeniosis } \\
\hline Religion & Respondents (n) & Contracted (\%) & P. value \\
Muslims & 80 & 42.5 & 0.012 \\
Christians & 312 & 58.3 & \\
Total & 392 & & \\
\hline
\end{tabular}


Taeniosis prevalence was higher in butchers and abattoir workers $(\mathrm{P}=0.000$ and $\chi^{2}=53.028$ ) than people from other sectors of occupation (farmers, merchants, students and civil servants) (Table 4).

Table 4: Prevalence of T. saginata by occupation of respondents.

\begin{tabular}{lccc}
\hline \multicolumn{3}{c}{ Taeniosis } \\
\hline Occupation & Respondents (n) & Contracted(\%) & P. value \\
Farmer & 142 & 66.2 & \\
Merchants & 47 & 57.4 & $<0.001$ \\
Butchers \& & 20 & 100 & \\
Abattoir workers & & & \\
Civil servants & 108 & 52.8 & \\
Students & 75 & 24 & \\
Total & 392 & & \\
\hline
\end{tabular}

Similarly, report of T. saginata infection was higher at all educational levels but more significant in illiterate (without formal education) respondents than in literate (elementary up to high school) and graduates (colleges and universities) $\left(\mathrm{P}=0.001\right.$ and $\left.\chi^{2}=13.972\right)$ (Table 5). It was also significantly high in people with raw meat consumption $(65.3 \%)$ habit than those who have never consumed $(16 \%)$ raw meat $(\mathrm{P}<0.001)$.

Table 5: Prevalence of Taenia saginata between education levels of respondents

\begin{tabular}{lccc}
\hline \multirow{2}{*}{ Education level } & \multicolumn{2}{c}{ Taeniosis } & P. value \\
\cline { 2 - 3 } Illiterate & 92 & Contracted (\%) & \\
literate & 190 & 71.7 & $<0.001$ \\
Graduates & 110 & 51.6 & \\
Total & 392 & 47.3 & \\
\hline
\end{tabular}


The logistic regression analysis also shows that raw meat consumption and occupation are the most important risk factors followed by respondent age, religion and sex (Table 6).

Table 6: Logistic regression analysis of questionnaire survey

\begin{tabular}{lllllll}
\hline Variable & Coefficient & df & p-value & OR & \multicolumn{2}{c}{$95 \%$ CI for OR } \\
\hline $\begin{array}{lllllll}\text { Consumption } \\
\text { of raw meat }\end{array}$ & 2.286 & 1 & 0.000 & 9.832 & 5.197 & 18.601 \\
$\begin{array}{l}\text { Occupation } \\
\text { Age }\end{array}$ & 1.825 & 1 & 0.000 & 6.201 & 3.290 & 9.366 \\
Religion & .639 & 1 & 0.000 & 2.740 & 1.617 & 4.643 \\
Sex & .441 & 1 & 0.012 & 1.894 & 1.152 & 3.114 \\
\hline
\end{tabular}

$\mathrm{df}=$ degree of freedom, $\mathrm{OR}=$ odds ratio, $\mathrm{CI}=$ confidence interval

\section{Discussion}

In the present study an overall prevalence $4.6 \%$ cysticercosis was registered at the three municipal abattoirs. Similar finding was reported by Markos Tibo (2001) in central Ethiopia and Nigatu Kebede et al.,(2009) at Addis Ababa Abattoir and in other endemic areas in Africa and Asia by other authors (Opara et al., 2006; Muneyeme et al., 2010; Garedaghi et al., 2011). Higher prevalence was reported from other abattoirs in the country: $18.49 \%$ in north western Ethiopia (Kebede, 2008); 26.25\% in Hawassa (Fufa Abunna et al., 2008) and $27.6 \%$ in Luna export abattoir in East Shoa (Hailu Degefu, 2005). In contrast lower prevalence $(3.20 \%)$ in cattle, in some parts of Ethiopia was reported by Cabaret et al., (2002). This may be associated with low infestation as reported by Garedaghi et al., (2011) or cysticerci could easily be missed as they may not be present on routine cuts since most cases of cysticercosis occur as light infestations. Moreover, inexperienced meat inspectors could most likely miss out quite number of viable cysticerci, which blend with the pinkish-red color of the meat and be passed for human consumption. The majority of the findings in Ethiopia were based on surveys carried out on carcasses subjected to routine meat inspection procedures. Hence, the same limitations with which meat inspection shares globally were reflected in the results of the present study. For instance, 
Onyango-Abuje et al., (1996) in low and high risk areas of Kenya reported 0 and $31.47 \%$ of prevalence by meat inspection and $13.33 \%$ and $80.42 \%$ prevalence by serology respectively. The absence of significant variation between the three study abattoirs may suggest that the source of cattle slaughtered, the sanitary conditions and raw meat consumption practices are similar. This is supported by the fact that the three abattoirs are separated by less than $100 \mathrm{~km}$ along the main road to Addis Ababa and all the meat produced are consumed locally.

The present abattoir study also revealed that among the organs accessible for detailed inspection, the heart, tongue and masseter muscle were the most affected. These preferred predilection sites for the cysts of Cysticercus were similar to earlier reports in Ethiopia (Hailu Degefu, 2005; Fufa Abunna et al., 2008) and various endemic areas (Okfar, 1988; Anosike, 2001; Cabaret et al., 2002; Opara et al., 2006). Overall, 39.3\% (22/56) of the cysts examined were viable with relatively higher viability among cysts collected from tongue and heart. This is in agreement with the findings of Fufa Abunna et al. (2008) who reported $44.2 \%$ live and $65.8 \%$ dead cysts in Hawassa abattoir (South Ethiopia). On the other hand, Nigatu Kebede (2008) recorded $85.6 \%$ viable and $14.4 \%$ degenerated or calcified cysts in North-west Ethiopia.

More than half $(55.1 \%)$ of the questionnaire survey respondents confirmed that they experienced tapeworm infection at least once in their life. This was manifested by the observation of proglottids in their feces and/or under wear. Because of religious and cultural reasons, pork is not consumed in the study areas as is the case in many parts of Ethiopia. Hence, the proglottids observed were likely to be of $T$. saginata. The response for human infection is lower than that indicated by previous studies in other areas: $64.2 \%$ (Fufa Abunna et al., 2008), and 68\% (Markos Tibo, 2001) possibly due to the difference in the composition of the respondents. On the other hand, there was similar degree of tapeworm infection among the three study sites suggesting the existence of similar risk factors and raw meat consumption practice. 
The present study showed that there was strong association between age of the respondents and the prevalence of $T$. saginta infection, which is in agreement with previous reports (Hailu Degefu, 2005; Fufa Abunna et al., 2008). Taeniosis was more reported from respondents above 20 years of age /adults than from younger respondents. This may imply that the habit of raw meat consumption increases with age. Younger people, mostly students cannot afford to buy beef for raw consumption as most raw meats are consumed at the butcher's house and are more expensive (of high quality) than the one that is taken away for preparation at home. The current result was also supported by Cabaret et al., (2002) where he reported a high prevalence of $T$. saginata/cysticercosis in sub-Saharan Africa especially East Africa.

In this study $T$. saginata was more prevalent in men than in women. Similar findings have also been reported previously (Markos Tibo, 2001; Hailu Degefu, 2005) in other parts of Ethiopia. This is possibly because of the fact that traditionally more men frequently visit butchers than women for raw beef consumption. Similarly, this study has also clearly demonstrated the impact of religion on raw meat consumption. The proportion of taeniosis infection was higher in the Christian respondents than in Muslim respondents. Markos Tibo (2001) and Fufa Abunna et al.,(2008) have also reported similar observations in different parts of Ethiopia suggesting that the tradition of raw beef consumption is more important in the Christian community.

Groups who had easy access to raw meat and meat products (Butchers and abattoir workers) and those people with low level of formal education were reported to be more infected than those who had low access to raw meat and those with better education. This implies that the frequency of raw beef consumption is higher in these groups of people. Similar findings were reported by previous studies in other parts of the country (Fufa Abunna et al., 2008; Nigatu Kebede et al., 2009). These results agree with the report of Murrel (2005) that indicated taeniosis as a more common health problem in population/age groups that consume raw meat or underc ooked beef meat.

In conclusion, bovine cysticercosis caused by C. bovis/Taenia saginata, are 
important problems in the study areas. There is no significant variation between the study sites for the prevalence of bovine cysticercosis. On the other hand, the questionnaire survey revealed that human taeniosis is more important in butchers and abattoir workers and illiterate people whereas the problem is lower in students and female respondents. Consumption of raw meat and occupation are the major predisposing factors. Intensive meat inspection, appropriate treatment of infected people and the use of latrine has to be encouraged to significantly reduce the problem in the areas.

\section{References}

Abunna, F., Tiahun, G., Megersa, B., Regassa, A., and Kumsa, B. 2008. Bovine Cysticercosis in Cattle Slaughtered at Hawassa Municipal Abattoir, Ethiopia: Prevalence, Cyst Viability, Distribution and its Public Health Implication. Zoonoses Pub. Hlth., 55: 82-88.

Anosike, J.C., 2001. Some observations on Taenia saginata/cysticercosis in slaughter cattle in Nigeria. Int. J. Zoonoses., 2: 82-89.

Arsham, H., 2002. Questionnaire Design and Surveys Sampling, SySurvey: The Online Survey Tool. http://home.ubalt.edu/ntsbarsh/Business-stat. Accessed on 20 March, 2013

Cabaret, J., Geerts, S., Madeline, M., Ballandonne, C., Barbier, D., 2002. The use of urban sewage sludge on pastures: The cysticercosis threat. Vet. Res., 33:575-597.

Dorny, P., Praet, N., 2007. Taenia saginata in Europe. Vet. Parasitol., 149 (1-2): 2224.

Dorny, P., Praet, N., Deckers., Gabriel S. 2009. Emerging food-born parasites. Vet. Parasitol., 163:196-206.

Dorny, P., Vercammen, F., Brandt, J.,Vansteenkiste, W.,Brekvens, D., Greets, S., 2000. Sero-epidemiological study of Taenia saginata cysticercosis in Belgian Cattle. Vet. Parasitol., 88: 43-49.

Garedaghi Y., Rezaii Saber, A.P., and Saberie Khoroshahi, M., 2011. Prevalence of bovine Cysticercosis of Slaughtered Cattle in Meshkinshahr Abattoir. Am J Anim. Vet. Sci., 6 (3): 121-124. 
Giesecke, W.H., 1997. Prevalence and economic implications of taeniasis/cysticercosis in South Africa. Report on a Workshop held at the Onderstepoort Veterinary Institute, Onderstepoort, South Africa, 18-19 August 1997. PP: 19 -70.

Degefu, H., 2005. Prevalence and risk factors for Taenia saginata Taeniosis/ Cysticercosis in three selected areas of Eastern Shoa, Ethiopia. MSc. Thesis, FVM, AAU, Debre Zeit, Ethiopia.

Kebede, N., 2008. Cysticercosis of slaughtered cattle in Northwestern Ethiopia. Res.Vet. Sci., 85 (3): 522-526.

Murrell, K.D., 2005. Epidemiology of taeniosis and cysticercosis. In: Murrel. K.D. (Ed), WHO/FAO/OIE. Guideline for surveillance, prevention and control of taeniosis and cyaticercosis. World Health Organization for Animal Health (OIE) Paris, pp: 27-43.

Muneyeme, M., Munangandu, H.M., Muma, J.B., Nambota, A.M., and Biffa D., 2010. Investigating effects of parasite infection on body condition of the Kafue basin. BMC Res. Notes, 3:346-346.

Ministry of Agriculture, 1972. Meat inspection Regulation Legal Notice No. 428, Neg arit Gazeta, Addis Ababa, Ethiopia.

Kebede, N., Tilahun, G., and Degefu, H., 2009. Current status of bovine cysticercosis of slaughtered cattle in Addis Ababa Abattoir, Ethiopia. Trop.Anim.Hlth. Prod., 41:291-4.

Onyango-Abuje, J. A., Joseph, M. N., Moses, K., Steven, H. W., Patrick, L., Gwenda, H. and Leslie, J. S. H. 1996 Seroepidemiological survey of Taenia saginata cysticercosis in Kenya. Vet. Parasitol., 64: 177-185.

Okafor, F.C., 1988. Epizootiology of Cysticercus bovis in Imo State, Nigeria. Parasitol., 29: 25-30.

Opara, M. N., Ukpong, U. M., Okoli, I. C., Anosike, J. C., 2006. Cysticercosis of Slaughtered Cattle in Southeastern Nigeria. Ann. N.Y. Acad. Sci., 1081: 339-346. 
Pawlowski, Z.S., Murrell, K.D., 2001. Taeniasis and cysticercosis. In: Hui Y.H., Sattar S.A., Murrell K.D., Nip W-K., Stanfield P.S. (Eds.) Food-borne Disease Handbook, 2nd ed. New York: Marcel Dekker, pp: 217-227.

Stata Corp. 2001. Statistical Software Release 7.1. Lake way Drive. College Station. TX

Tibo, M., 2001. Epidemiology of T. saginata, Taeniosis/Cysticercosis in Threeselected Agro climatic Zones in Central Ethiopia. MSc. Thesis, FVM, AAU-Free University of Berlin, Germany and Ethiopia.

Thrusfield, M.V., 2005. Veterinary epidemiology. $3^{\text {rd }}$ Edition, Black well Science Ltd, UK, pp: 231-234. 